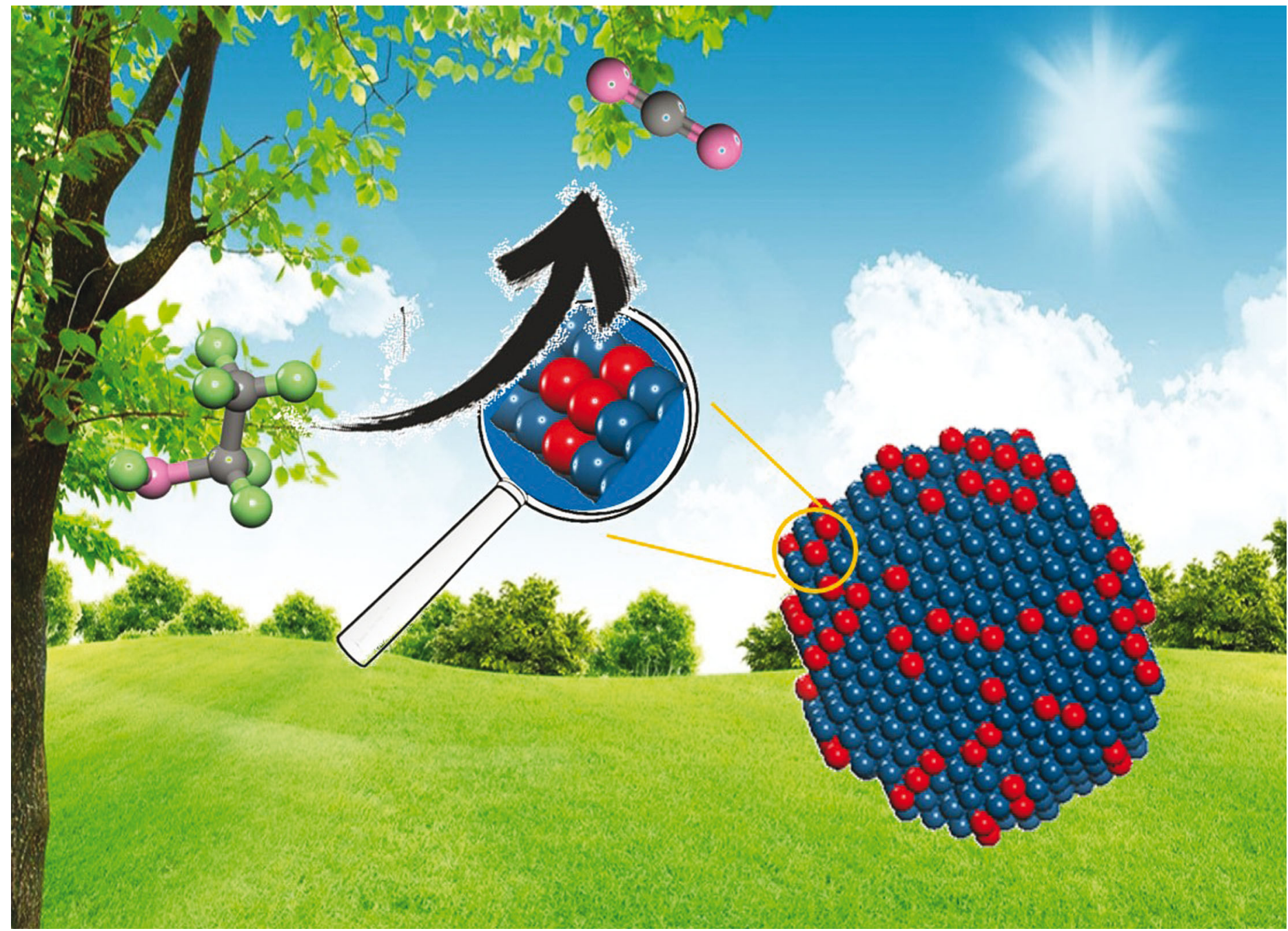

Showcasing research from the laboratory of Prof. Shi-Gang Sun at the Collaborative Innovation Centre of Chemistry for Energy Materials (iChEM), Xiamen University, China.

Title: Elucidation of the surface structure-selectivity relationship in ethanol electro-oxidation over platinum by density functional theory

This work successfully builds a general framework to comprehend the structure-selectivity relationship in ethanol electro-oxidation over platinum catalysts by density functional theory calculations. Based on the investigation of the reaction mechanisms on three basal planes and five stepped surfaces, it is identified that only (110) and $n(111) \times(110)$ sites can enhance $\mathrm{CO}_{2}$ selectivity but other non-selective step sites are more beneficial to activity. This work gives insights into the catalytic process on practical catalysts with various surface sites, which is essential for the search of new highly active and selective catalysts.

\section{As featured in:}

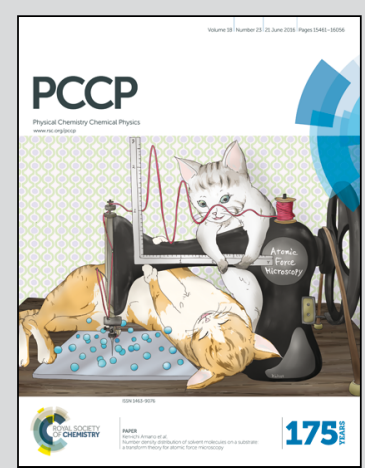

See Tian Sheng, Shi-Gang Sun et al., Phys. Chem. Chem. Phys., 2016, 18, 15501.

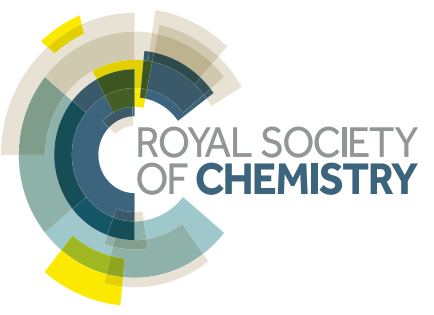




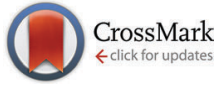

Cite this: Phys. Chem. Chem. Phys., 2016, 18, 15501

Received 14th April 2016, Accepted 5th May 2016

DOI: $10.1039 / c 6 c p 02484 j$

www.rsc.org/pccp

\title{
Elucidation of the surface structure-selectivity relationship in ethanol electro-oxidation over platinum by density functional theory $\dagger$
}

\author{
Tian Sheng, ${ }^{\star a}$ Wen-Feng Lin ${ }^{b}$ and Shi-Gang Sun ${ }^{\star^{a}}$
}

\begin{abstract}
We have successfully built a general framework to comprehend the structure-selectivity relationship in ethanol electrooxidation on platinum by density functional theory calculations. Based on the reaction mechanisms on three basal planes and five stepped surfaces, it was found that only (110) and $n(111) \times(110)$ sites can enhance $\mathrm{CO}_{2}$ selectivity but other non-selective step sites are more beneficial to activity.
\end{abstract}

The use of direct ethanol fuel cells (DEFCs) is a hopeful future energy solution for directly converting chemical energy into electricity to replace the usage of fossil fuels. Liquid ethanol, which can be sustainably produced from biomass, has a high energy density and is stored and transported easily compared to hydrogen gas. However, there are still challenges hindering DEFCs' widespread applications commercially, in particular, the slow ethanol oxidative kinetics and formation of some poisoning intermediates. Platinum catalysts are the most common in fuel cell systems operating under strongly acidic conditions and thus, understanding of the catalytic processes on platinum catalysts is fundamentally important. ${ }^{1-7}$ The complete oxidation of ethanol to $\mathrm{CO}_{2}$ is the ideal anodic reaction in DEFCs, with 12 electron transfer $\left(\mathrm{C}_{2} \mathrm{H}_{5} \mathrm{OH}+3 \mathrm{H}_{2} \mathrm{O} \rightarrow 2 \mathrm{CO}_{2}+12 \mathrm{H}^{+}+12 \mathrm{e}^{-}\right)$, but in reality, acetaldehyde $\left(\mathrm{C}_{2} \mathrm{H}_{5} \mathrm{OH} \rightarrow \mathrm{CH}_{3} \mathrm{CHO}+2 \mathrm{H}^{+}+2 \mathrm{e}^{-}\right)$and acetic acid $\left(\mathrm{C}_{2} \mathrm{H}_{5} \mathrm{OH}+\mathrm{H}_{2} \mathrm{O} \rightarrow \mathrm{CH}_{3} \mathrm{COOH}+4 \mathrm{H}^{+}+4 \mathrm{e}^{-}\right)$predominate the final products, with only 2 and 4 electron transfer, respectively. ${ }^{1-7}$ The optimal catalyst for ethanol oxidation is inevitably linked with $\mathrm{CO}_{2}$ selectivity which is expected to be highly active towards cleaving the $\mathrm{C}-\mathrm{C}$ bond at low potentials. Unfortunately, the production of $\mathrm{CO}_{2}$ is identified in the region of $0.5-7.5 \%$ on platinum catalysts in real systems, ${ }^{2}$ which is far below the desirable selectivity for implementation of the technology.

\footnotetext{
${ }^{a}$ Collaborative Innovation Centre of Chemistry for Energy Materials, State Key Laboratory of Physical Chemistry of Solid Surfaces, Xiamen University, Xiamen, 361005, China.E-mail: tsheng@xmu.edu.cn, sgsun@xmu.edu.cn

${ }^{b}$ Department of Chemical Engineering, Loughborough University, Loughborough, Leicestershire, LE11 3TU, UK

$\dagger$ Electronic supplementary information (ESI) available. See DOI: 10.1039/c6cp02484j
}

Understanding the structure-selectivity relationship at atomic levels is one of the fundamental scientific challenges in surface science and catalysis, which is of great significance for rationally designing catalysts. For practical catalysts with a high complexity of surface structures, what sites may actually govern the product distribution is largely unresolved due to the current technological limitation in revealing the detailed selectivity at different surface sites. Surface structural effects on ethanol electrooxidation have been studied by using single-crystal planes or nanoparticles enclosed by unique facets, and the low-coordination sites on the surface have been identified to facilitate the reaction rate. ${ }^{8-16}$ However, in terms of selectivity, the low-coordination sites do not always promote $\mathrm{CO}_{2}$ selectivity. Experiments have shown that the formation of acetic acid was also enhanced by the presence of low-coordination sites. ${ }^{8,11}$ The formation of $\mathrm{CO}_{2}$ is sensitive to the surface structure, and surfaces with terraces of (111) symmetry separated by monoatomic (110) step sites were found to be very active for $\mathrm{C}-\mathrm{C}$ bond breaking since the amounts of $\mathrm{CO} / \mathrm{CO}_{2}$ produced increase with the step density. ${ }^{8-12,15,16}$

The Brnsted-Evans-Polanyi (BEP) relationship reveals that the thermodynamics of any catalytic reaction controls the kinetics in general. ${ }^{17-20}$ Since $\mathrm{CO}_{2}$ is considerably more stable than acetaldehyde and acetic acid as the major products in ethanol electrooxidation, the thermodynamically favored $\mathrm{CO}_{2}$ production is expected to be faster kinetically than acetic acid production, but in fact the $\mathrm{CO}_{2}$ selectivity is rather low. The underlying reason behind the low $\mathrm{CO}_{2}$ selectivity is believed to be the kinetics, which may significantly determine the reaction route. Therefore, a fundamental understanding of ethanol selective oxidation reactions is significant for elucidating the structureselectivity relationship at the atomic level, also shedding light on the selectivity concerned in many other electrocatalytic systems.

To date, a general framework for describing the structureselectivity relationship in ethanol electrooxidation is still lacking, and many puzzles regarding the catalytic selectivity of different sites have not been rationalized yet. In particular, the following questions remain to be solved: What is the key factor determining the complete oxidative (to form $\mathrm{CO}_{2}$ ) or partial oxidative 
(to form acetic acid) pathway? Why were (110) step sites on the (111) terrace found experimentally to be excellent for considerably enhancing $\mathrm{CO}_{2}$ selectivity? Are there any possible sites having a high selectivity towards $\mathrm{CO}_{2}$ ? With all these questions in the mind, we present a detailed study on how platinum surface sites may affect the reaction mechanism, kinetics and selectivity for ethanol electrooxidation by using first-principles calculations. Three basal planes and five typical stepped surfaces with different atomic arrangements of reactive sites were employed for studying the structural effects. By analysing the kinetics, the significance of $\beta$-dehydrogenation in $\mathrm{CH}_{3} \mathrm{CHOH}^{*}$ is illustrated and the structure-selectivity relationship is thus revealed.

Platinum single-crystal planes defined by Miller indices provide a variety of surface structures with different atomic arrangements, conventionally by a unit stereographic triangle as shown in Fig. 1. ${ }^{27,28}$ Three vertices of the triangle represent the three basal planes, i.e., flat (111) and (100), and stepped (110). The three side-lines of the triangle represent the [011] , [110], and [001] crystallographic zones where the planes exhibit a terracestep structure with different types of step sites. In the [001] and [011] zones, two types of step sites exist, i.e., $\operatorname{Pt}(211)$ vs. $\operatorname{Pt}(511)$ and $\mathrm{Pt}(310)$ vs. $\mathrm{Pt}(320)$, on which the local structures of the step sites are different. The reactive sites on $\mathrm{Pt}(211)$ and $\mathrm{Pt}(511)$ are $n(111) \times(100)$ and $n(100) \times(111)$ steps, and those on $\mathrm{Pt}(310)$ and $\mathrm{Pt}(320)$ are $n(100) \times(110)$ and $n(110) \times(100)$ steps. But in the [110] zone, the step structures of $n(111) \times(110)$ and $n(110) \times(111)$ are the same due to the (111) symmetry, leading to only $\mathrm{Pt}(331)$ being used. All the calculations reported here are performed using the VASP code and the computational details can be seen in the ESI. $\dagger$ It is worth noting that, in the theoretical calculation, the reaction is localized on steps, hence the overall effects between terraces and steps are not considered, ${ }^{16,29}$ which is different from the experimental results obtained on single crystal planes where the catalytic reactivity includes both steps and terraces. The ethanol electrooxidation mechanism is rather complicated

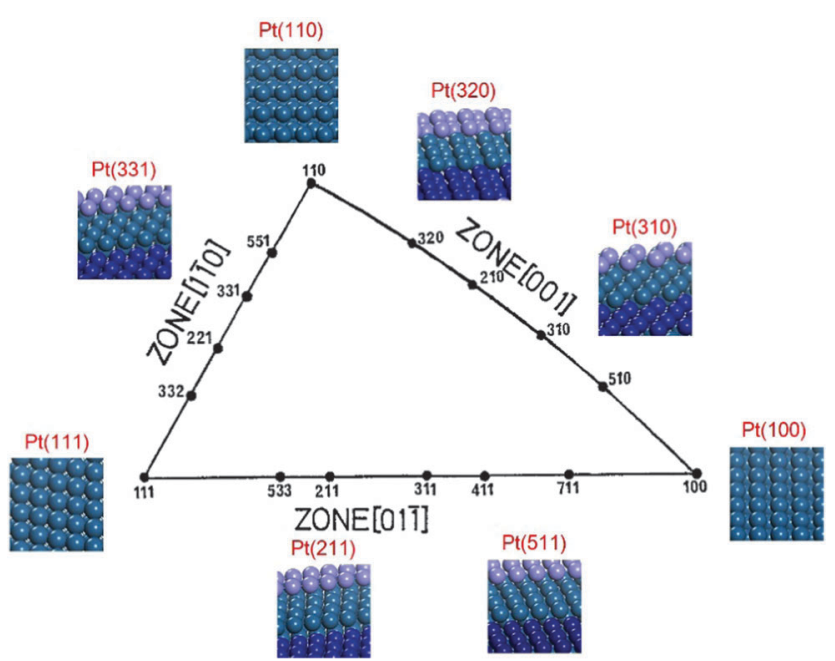

Fig. 1 Unit stereographic triangle of platinum single-crystal surfaces and the models of surface atomic arrangements. including over 40 possible intermediates. The reaction mechanisms of ethanol electrooxidation are calculated, respectively, on the above surfaces. ${ }^{20-26}$ All the calculated data with reaction energies and kinetic barriers are listed in Table S2 (ESI $\dagger$ ), the energy profiles are shown in Fig. S2 (ESI $\dagger$ ), and all the structures of optimized intermediates and transition states are shown in Fig. S3 (ESI $\dagger$ ). Initially, the dehydrogenation of ethanol preferably starts from breaking the $\alpha-\mathrm{C}-\mathrm{H}$ bond, forming $\mathrm{CH}_{3} \mathrm{CHOH}^{*}$. $\mathrm{CH}_{3} \mathrm{CHOH}^{*}$ is found to be not only able to break the $\alpha-\mathrm{C}-\mathrm{H}$ bond but also capable of breaking the $\beta-\mathrm{C}-\mathrm{H}$ bond. Thus, during the formation of $\mathrm{CH}_{2} \mathrm{CO}^{*}$ from which the $\mathrm{C}-\mathrm{C}$ bond breaking would occur inevitably, two pathways need to be considered respectively. ${ }^{20-26}$ If the $\alpha$-dehydrogenation pathway follows, the reaction route would be $\mathrm{CH}_{3} \mathrm{CHOH}^{*} \rightarrow \mathrm{CH}_{3} \mathrm{COH}^{*} \rightarrow \mathrm{CH}_{3} \mathrm{CO}^{*} \rightarrow$ $\mathrm{CH}_{2} \mathrm{CO}^{*}$; on the other hand, if the $\beta$-dehydrogenation pathway follows, the reaction path would be $\mathrm{CH}_{3} \mathrm{CHOH}^{*} \rightarrow \mathrm{CH}_{2} \mathrm{CHOH}^{*} \rightarrow$ $\mathrm{CH}_{2} \mathrm{COH}^{*} \rightarrow \mathrm{CH}_{2} \mathrm{CO}^{*}$. Fig. 2 shows the reaction mechanism for ethanol selective dehydrogenation with the structures of key intermediates on $\mathrm{Pt}(111)$.

In the $\alpha$-dehydrogenation pathway, we find that once $\mathrm{CH}_{3} \mathrm{CO}^{*}$ forms on the surface it would be oxidized by surface oxidants derived from water dissociation at high potentials to produce acetic acid $\left(\mathrm{CH}_{3} \mathrm{COOH}^{*}\right)$, and the further decomposition of $\mathrm{CH}_{3} \mathrm{CO}^{*}$ to $\mathrm{CH}_{2} \mathrm{CO}^{*}$ via $\beta-\mathrm{C}-\mathrm{H}$ bond breaking is rather difficult since the barriers are very high which are not favoured kinetically at room temperature. $\mathrm{CH}_{3} \mathrm{CO}^{*}$ on $\mathrm{Pt}(511)$ is the most stable one due to the highest decomposition barrier of $0.95 \mathrm{eV}$. The most active surfaces are $\mathrm{Pt}(320)$ and $\mathrm{Pt}(110)$ for $\mathrm{CH}_{3} \mathrm{CO}^{*}$ dehydrogenation with barriers of $0.79 \mathrm{eV}$ and $0.82 \mathrm{eV}$, respectively. On the other surfaces, the barriers are $\sim 0.90 \mathrm{eV}$. Although C1 products are more thermodynamically favored than $\mathrm{CH}_{3} \mathrm{CO}^{*}$, the high stability of $\mathrm{CH}_{3} \mathrm{CO}^{*}$ prevents its further decomposition kinetically. That is, once the $\alpha$-dehydrogenation occurs in $\mathrm{CH}_{3} \mathrm{CHOH}^{*}$, the final dehydrogenation product on the surface has to be $\mathrm{CH}_{3} \mathrm{CO}^{*}$.

In contrast, in the $\beta$-dehydrogenation pathway for the formation of $\mathrm{CH}_{2} \mathrm{CO}^{*}$, which does not involve the formation of $\mathrm{CH}_{3} \mathrm{CO}^{*}$, the barrier is much reduced. The comparison of the overall barriers in the two pathways is presented in Fig. 3. It is apparent that the barriers in the $\beta$-dehydrogenation pathway (the red columns) are all lower than those in the $\alpha$-dehydrogenation

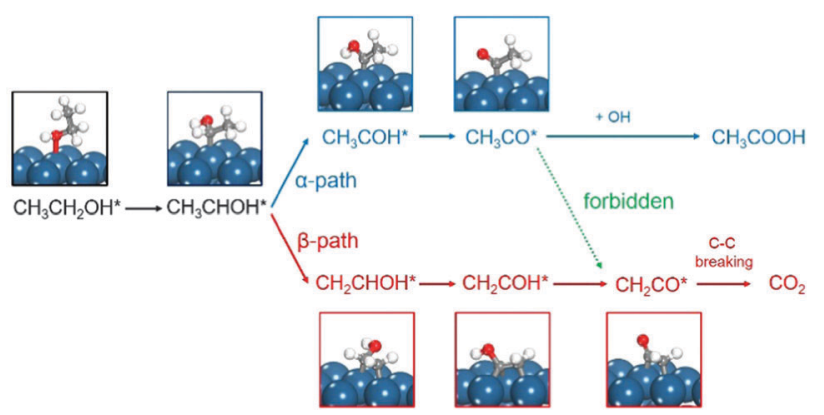

Fig. 2 Reaction mechanism for ethanol selective dehydrogenation via the $\alpha$-dehydrogenation pathway (blue) or the $\beta$-dehydrogenation pathway (red). The key intermediate structures on $\mathrm{Pt}(111)$ are displayed. 


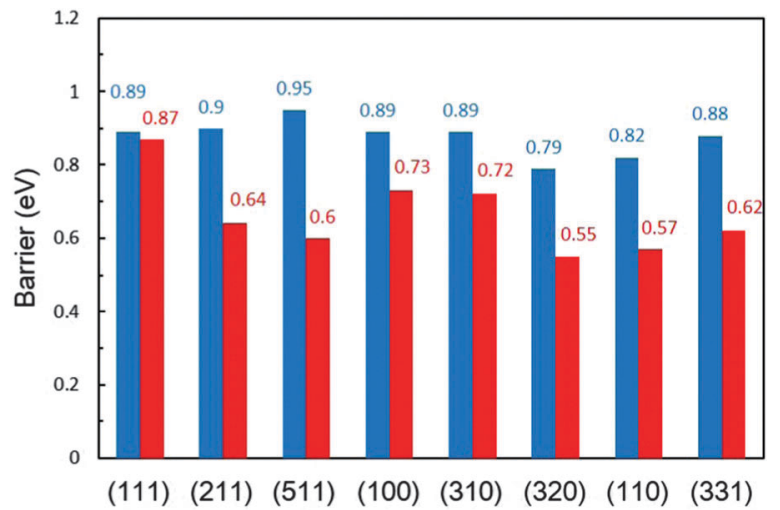

Fig. 3 Comparison of the overall barriers (in eV) for $\mathrm{CH}_{3} \mathrm{CHOH}^{*}$ dehydrogenation to $\mathrm{CH}_{2} \mathrm{CO}^{*}$ via the $\alpha$-dehydrogenation (blue) and $\beta$-dehydrogenation (red) pathways on a series of Pt surfaces.

pathway (the blue columns). The smallest overall barrier difference between the two pathways is obtained on $\operatorname{Pt}(111)$, i.e., $0.87 \mathrm{eV}$ via the $\beta$-dehydrogenation pathway and $0.89 \mathrm{eV}$ via the $\alpha$-dehydrogenation pathway, indicating that the reaction rates for the formation of $\mathrm{CH}_{2} \mathrm{CO}^{*}$ via the two pathways are rather close. But on the other surfaces, the advantage of the $\beta$-dehydrogenation pathway in kinetics is considerable owing to a lower barrier of $0.16-0.35 \mathrm{eV}$, which would result in increasing the rate at about two to four orders of magnitude compared with that via the $\alpha$-dehydrogenation pathway at room temperature. It is therefore suggested that the $\beta$-dehydrogenation pathway is more favoured kinetically for $\mathrm{C}-\mathrm{C}$ bond breaking.

Whether $\mathrm{CH}_{2} \mathrm{CO}^{*}$ or $\mathrm{CHCO}^{*}$ is a reasonable precursor for $\mathrm{C}-\mathrm{C}$ bond splitting is found to be dependent on the surface structure. ${ }^{30}$ We have thus examined the two possible pathways: (i) $\mathrm{CH}_{2} \mathrm{CO}^{*} \rightarrow \mathrm{CHCO}^{*} \rightarrow \mathrm{CH}^{*}+\mathrm{CO}^{*}$ and (ii) $\mathrm{CH}_{2} \mathrm{CO}^{*} \rightarrow \mathrm{CH}_{2}^{*}+$ $\mathrm{CO}^{*}$, respectively. If the dehydrogenation barrier is lower than the $\mathrm{C}-\mathrm{C}$ bond breaking barrier, it would suggest the dehydrogenation to $\mathrm{CHCO}^{*}$ could occur first. The comparison barriers between paths (i) and (ii) are displayed in Fig. S4 (ESI $\dagger$ ). From our results, on $\mathrm{Pt}(111), \operatorname{Pt}(100)$ and $\mathrm{Pt}(310)$, the mechanism follows path (i), while on other five surfaces, the $\mathrm{C}-\mathrm{C}$ bond breaking in $\mathrm{CH}_{2} \mathrm{CO}^{*}$ may occur directly without involving the formation of $\mathrm{CHCO}^{*}$. According to the favoured pathways, the $\mathrm{C}-\mathrm{C}$ bond breaking barriers on different surfaces are presented in Fig. S5 (ESI $\dagger$ ). It can be seen that all the barriers are $0.48-0.77 \mathrm{eV}$, indicating that the $\mathrm{C}-\mathrm{C}$ bond breaking rate is reasonable kinetically. Once $\mathrm{CH}_{2}{ }^{*}$ is produced from $\mathrm{CH}_{2} \mathrm{CO}^{*}$, it would be further decomposed into $\mathrm{CH}^{*}$ which is stable on the surface since the further $\mathrm{C}^{*}$ formation is prohibited by thermodynamics or kinetics. As a result of $\mathrm{C}-\mathrm{C}$ bond breaking, one would expect the final $\mathrm{C} 1$ products to be $\mathrm{CH}^{*}$ and $\mathrm{CO}^{*}$ on major surfaces.

From the above kinetic analyses, it is shown that the selectivity towards $\mathrm{CO}^{*}$ formation versus that towards $\mathrm{CH}_{3} \mathrm{CO}^{*}$ formation on platinum is determined by the competition between the elementary step of $\mathrm{CH}_{3} \mathrm{CHOH}^{*} \rightarrow \mathrm{CH}_{3} \mathrm{COH}^{*}$ and the step of $\mathrm{CH}_{3} \mathrm{CHOH}^{*} \rightarrow$ $\mathrm{CH}_{2} \mathrm{CHOH}^{*}$. The barriers in $\mathrm{C}-\mathrm{C}$ bond breaking steps being presented are reasonably low, such that the origin of low $\mathrm{CO}_{2}$ selectivity should date back to the selective dehydrogenation in $\mathrm{CH}_{3} \mathrm{CHOH}^{*}$. Only when the $\beta$-dehydrogenation pathway is preferred kinetically than the $\alpha$-dehydrogenation pathway in $\mathrm{CH}_{3} \mathrm{CHOH}^{*}$, ethanol $\mathrm{C}-\mathrm{C}$ bond breaking can occur. We thus defined the selectivity as the difference between the barrier of $\alpha$-dehydrogenation $\left(E_{\mathrm{a}, \alpha-\mathrm{CH}}\right)$ and that of $\beta$-dehydrogenation $\left(E_{\mathrm{a}, \beta-\mathrm{CH}}\right)$ as follows:

$$
\Delta E_{\mathrm{a}}=E_{\mathrm{a}, \alpha-\mathrm{CH}}-E_{\mathrm{a}, \beta-\mathrm{CH}}
$$

Quantitatively, the higher $\Delta E_{\mathrm{a}}$ indicates the more favoured $\beta$-dehydrogenation and the higher possibility of forming $\mathrm{C} 1$ products. ${ }^{23}$ The comparison of the selectivities obtained on a series of Pt surfaces is shown in Fig. 4, based on the above definition. It is found that the stepped $\mathrm{Pt}(110)$ surface possesses the highest selectivity with $\Delta E_{\mathrm{a}}$ being $0.13 \mathrm{eV}$, indicating that the predominant products ( $>99 \%$, estimated by the Boltzmann distribution) on the surface would be $\mathrm{CH}^{*}$ and $\mathrm{CO}^{*}$ at low potentials. Upon increasing the width of the (111) terrace, (110) step sites could still hold the selectivity. On Pt(331), the selectivity is reduced to $82 \%$, lower than that on $\mathrm{Pt}(110)$. Although having the same local structure of (110) sites, the presence of (111) terrace lowers the selectivity, indicating that the width of the terrace may affect the intrinsic properties of the step sites.

In the $[01 \overline{1}]$ zone, $\Delta E_{\mathrm{a}}$ is $-0.22 \mathrm{eV}$ on $\mathrm{Pt}(111)$ and $-0.19 \mathrm{eV}$ on $\mathrm{Pt}(100)$, respectively, suggesting that hardly any $\mathrm{C} 1$ product can form on the surface. The monoatomic (100) step on the (111) terrace, as the most common defect on surfaces, presents a moderate ability to break the $\mathrm{C}-\mathrm{C}$ bond, although it is not comparable with the selectivities on $\mathrm{Pt}(110)$ and $\mathrm{Pt}(331)$; about $32 \%$ ethanol on the $\mathrm{Pt}(211)$ step would decompose into $\mathrm{CH}^{*}$ and $\mathrm{CO}^{*}$ finally. However, the monoatomic (111) step on the (100) terrace cannot promote $\mathrm{CO}_{2}$ selectivity. The selectivity obtained on $\mathrm{Pt}(511)$ is almost the same as that on $\mathrm{Pt}(100)$. Herein, in the [011] zone, only upon increasing the density of $n(111) \times(100)$ step sites, the selectivity can be enhanced. In the [001] zone, despite the selectivities on $\operatorname{Pt}(320)$ and $\operatorname{Pt}(310)$ being better than that on $\mathrm{Pt}(100)$, the former two surfaces still cannot provide any C1 product, indicating that the increase of step sites in this zone is not beneficial to $\mathrm{CO}_{2}$ production.

The overall barriers in their kinetically favoured pathways can depict appropriately the activity in ethanol dehydrogenation on different surfaces. It can be seen from Table 1 that $\mathrm{Pt}(111)$ is the least active for ethanol dehydrogenation with the highest barrier

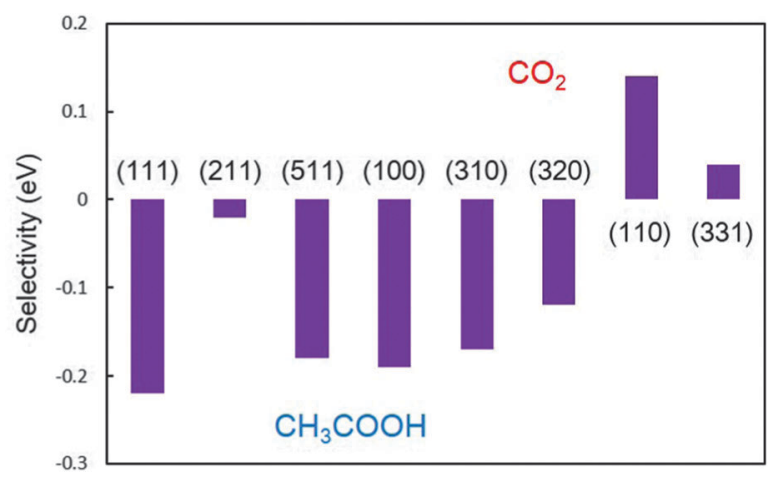

Fig. 4 Comparison of the selectivity $\left(\Delta E_{\mathrm{a}}\right.$, in $\left.\mathrm{eV}\right)$ on a series of Pt surfaces. 
Table 1 Calculated activity $\left(E_{\mathrm{a}}\right.$, in $\left.\mathrm{eV}\right)$ and selectivity $\left(\Delta E_{\mathrm{a}}\right.$, in $\left.\mathrm{eV}\right)$ on a series of Pt surfaces

\begin{tabular}{lrrrrrrrr}
\hline & $(111)$ & $(211)$ & $(511)$ & $(100)$ & $(310)$ & $(320)$ & $(110)$ & $(331)$ \\
\hline$E_{\mathrm{a}}$ & 0.78 & 0.54 & 0.51 & 0.64 & 0.54 & 0.52 & 0.68 & 0.70 \\
$\Delta E_{\mathrm{a}}$ & -0.22 & -0.02 & -0.18 & -0.19 & -0.17 & -0.12 & 0.14 & 0.04
\end{tabular}

of $0.78 \mathrm{eV}$ and $\mathrm{Pt}(100)$ is more active with a lower barrier of 0.64 eV. Pt(211), Pt(511), Pt(310) and Pt(320) steps are the most active where the barriers are between 0.51 and $0.54 \mathrm{eV}$. The activities on $\mathrm{Pt}(110)$ and $\mathrm{Pt}(331)$ are similar with the overall barriers being 0.68 and $0.70 \mathrm{eV}$, which are determined by the $\mathrm{C}-\mathrm{C}$ bond breaking barriers. The activities are in the following order:

$(111)<(110) \approx(331)<(100)<(310) \approx(211) \approx(320) \approx(511)$

From these results, it is understood that the presence of (110) or $n(111) \times(110)$ step sites may give rise to a high $\mathrm{CO}_{2}$ selectivity on practical catalysts, successfully explaining the experimental observations. ${ }^{8-12,15,16}$ However, the activities of such sites are less than other typical step sites, on which the partial oxidation to acetic acid is preferred. The reactive selectivity is strongly dependent on the local structure of the step sites and the lowcoordination sites are not always active for $\mathrm{C}-\mathrm{C}$ bond breaking. These findings highlight the need for control of the surface structure that will allow facile $\mathrm{C}-\mathrm{C}$ bond breaking but hardly provide a high activity at the same time. It is reasonable to infer that how to balance the selectivity and activity will be more crucial for making platinum catalysts more efficient. It is hardly possible that pure platinum catalysts are sufficiently active for complete ethanol electrooxidation to $\mathrm{CO}_{2}$ without acetic acid as the partial oxidation product in DEFCs.

In summary, we have successfully built a general framework to comprehend the surface structure-selectivity relationship in ethanol electrooxidation on platinum catalysts. The reasonable formation mechanisms for the $\mathrm{C} 1$ products are pointed out via the $\beta$-dehydrogenation pathway from $\mathrm{CH}_{3} \mathrm{CHOH}^{*}$. The selectivity is defined as the barrier difference based on the kinetic analyses. It is found that only (110) and $n(111) \times(110)$ step sites may enhance $\mathrm{CO}_{2}$ selectivity but other non-selective step sites are more beneficial to the activity towards partial oxidation. This work could help gain more insights into the catalytic processes on practical catalysts with various surface sites, which is essential for the search for new highly active and selective catalysts.

This work was supported by the NSFC (21361140374, 21321062 and 21573183) and the EPSRC (EP/I013229/1).

\section{Notes and references}

1 E. Antolini, J. Power Sources, 2007, 170, 1.

2 H. Wang, Z. Jusys and R. J. Behm, J. Phys. Chem. B, 2004, 108, 19413.

3 P. E. Tsiakaras, J. Power Sources, 2007, 171, 107.
4 A. Rabis, P. Rodriguez and J. T. Schmidt, ACS Catal., 2012, 2, 864.

5 F. Vigier, S. Rousseau, C. Coutanceau, J. M. Leger and C. Lamy, Top. Catal., 2006, 40, 111.

6 H. Nonaka and Y. Matsumura, J. Electroanal. Chem., 2002, 520, 101.

7 H. Hitmi, E. M. Belgsir, J. M. Leger, C. R. Lamy and O. Lezna, Electrochim. Acta, 1994, 39, 407.

8 J. Shin, W. J. Tornquist, C. Korzeniewski and C. S. Hoaglund, Surf. Sci., 1996, 364, 122.

9 J. Tarnowski and C. Korzeniewski, J. Phys. Chem. B, 1997, 101, 253.

10 F. Colmati, G. Tremiliosi-Filho, E. R. Gonzalez, A. Berna, E. Herrero and J. M. Feliu, Faraday Discuss., 2009, 140, 379.

11 F. Colmati, G. Tremiliosi, E. R. Gonzalez, A. Berna, E. Herrero and J. M. Feliu, Phys. Chem. Chem. Phys., 2009, 11, 9114.

12 J. Souza-Garcia, E. Herrero and J. M. Feliu, ChemPhysChem, 2010, 11, 1391.

13 C. Buso-Rogero, V. Grozovski, F. J. Vidal-Iglesias, J. SollaGullon, E. Herrero and J. M. Feliu, J. Mater. Chem. A, 2013, 1, 7068.

14 S. C. S. Lai and M. T. M. Koper, Faraday Discuss., 2008, 140, 399.

15 S. C. S. Lai and M. T. M. Koper, Phys. Chem. Chem. Phys., 2009, 11, 10446.

16 S. C. S. Lai and M. T. M. Koper, J. Phys. Chem. Lett., 2010, 1, 1122.

17 V. Pallassana and M. Neurock, J. Catal., 2000, 191, 301.

18 Z.-P. Liu and P. Hu, J. Chem. Phys., 2001, 114, 8244.

19 A. Logadottir, T. H. Rod, J. K. Norskov, B. Hammer, S. Dahl and C. J. H. Jacobsen, J. Catal., 2001, 197, 229.

20 R. Kavanagh, X. M. Cao, W. F. Lin, C. Hardacre and P. Hu, Angew. Chem., Int. Ed., 2012, 51, 1572.

21 H. F. Wang and Z. P. Liu, J. Am. Chem. Soc., 2008, 130, 10996.

22 T. Sheng, W. F. Lin, C. Hardacre and P. Hu, J. Phys. Chem. C, 2014, 118, 5762 .

23 T. Sheng, W. F. Lin, C. Hardacre and P. Hu, Phys. Chem. Chem. Phys., 2014, 16, 13248.

24 J. M. Jin, T. Sheng, X. Lin, R. Kavanagh, P. Hamer, P. Hu, C. Hardacre A. Martinez-Bonastre, J. Sharman, D. Thompsett and W. F. Lin, Phys. Chem. Chem. Phys., 2014, 16, 9432.

25 D. D. Hibbitts and M. Neurock, J. Catal., 2013, 299, 261.

26 B. Braunchweig, D. Hibbitts, M. Neurock and A. Wieckowski, Catal. Today, 2013, 202, 197.

27 J. F. Nicholas, An Atlas of Models of Crystal Surfaces; Gordon \& Breach, New York, 1965.

28 N. Tian, Z. Y. Zhou and S. G. Sun, J. Phys. Chem. C, 2008, 112, 19801.

29 N. Hoshi, K. Kida, M. Nakamura, M. Nakada and K. Osada, J. Phys. Chem. B, 2006, 110, 12480.

30 R. Alcala, M. Mavrikakis and J. A. Dumesic, J. Catal., 2003, 218, 178. 